\section{The key to the past?}

\section{Richard B. Alley}

acking an actual time machine for studying volcanoes, drifting continents, dinosaurs and other denizens of the past, Earth scientists have to read the histories written in the pages of sediments. To do this, geologists have to use the relation between modern processes and their sedimentary products as a Rosetta Stone to translate ancient sediments into the grand story of the Earth. This use of the present as the key to the past is called uniformitarianism - but just how uniform was the past?

The first uniformitarian was probably James Hutton, who observed in the late 1700 s that the passing of centuries had worked only small changes to a Roman wall in England, whereas much larger changes had broken rocks into pebbles and sand. By ignoring the constraints of scriptures and considering the possibility of an old world, Hutton found that he could explain geology as the product of processes still acting, without recourse to the supernatural or the catastrophic.

Hutton's uniformitarian ideas were rescued from his poor writing and distributed widely by Charles Lyell during the mid-1800s. However, perhaps overreacting to the persistence of Biblical literalists, Lyell took uniformitarianism to an extreme, arguing not only that modern processes acted in the past to shape the Earth, but that those processes have always occurred at similar rates.

Lyell gave Charles Darwin the vast ages on which to stage evolution. Although thus advancing biology, Lyell may have delayed the study of the origins and early evolution of Earth, the environment and life itself by taking too literally Hutton's "no vestige of a beginning, no prospect of an end".

Lyell never observed the impact of a large meteorite or the evidence for an almost totally frozen 'snowball Earth'; most of his examples were drawn from the last eighth of
Earth's history. Our present-day, broader view of events and ages has moved us back towards Hutton's uniformity of 'physical law' or of principles of behaviour. Rates and even dominant processes may change, but the underlying order of physics, chemistry and biology remains.

Oddly enough, while deep-time geologists have been quietly moving away from the Lyellian uniformitarianism designed for them, the concept lives on in palaeoclimatology. The possibility of anthropogenic or natural climate change affecting societies and ecosystems drives a small army of researchers trying to understand and even predict the behaviour of the Earth system. The history of the system is used in construction and testing of models, and the more quantitative that history, the better. That history is written in sea-floor muds, tree rings, cave formations and other sedimentary archives. Literally hundreds of physical, chemical, isotope and biological palaeoclimate indicators are used.

The palaeoclimate technique is the essence of simplicity: (1) relate some characteristic(s) of sediment to some characteristic(s) of climate, by measuring how they vary together now in different places, or over the short times of instrumental records; (2) assume that this relation was the same at a place over different times in the past; (3) measure the appropriate characteristic(s) on older sediment; and (4) calculate the past climate characteristic(s). One needs good instruments, accurate dating techniques and the ability to sample the old sediments and to measure the right things. But with enough money, mass spectrometers, drill ships and brilliant graduate students, the procedure is straightforward.

But the spirit of Lyell is lurking. As R. S. Bradley wrote in his influential text: "It is assumed that the modern relationships observed have operated, unchanged, throughout the period of interest (the principle of uniformitarianism)."

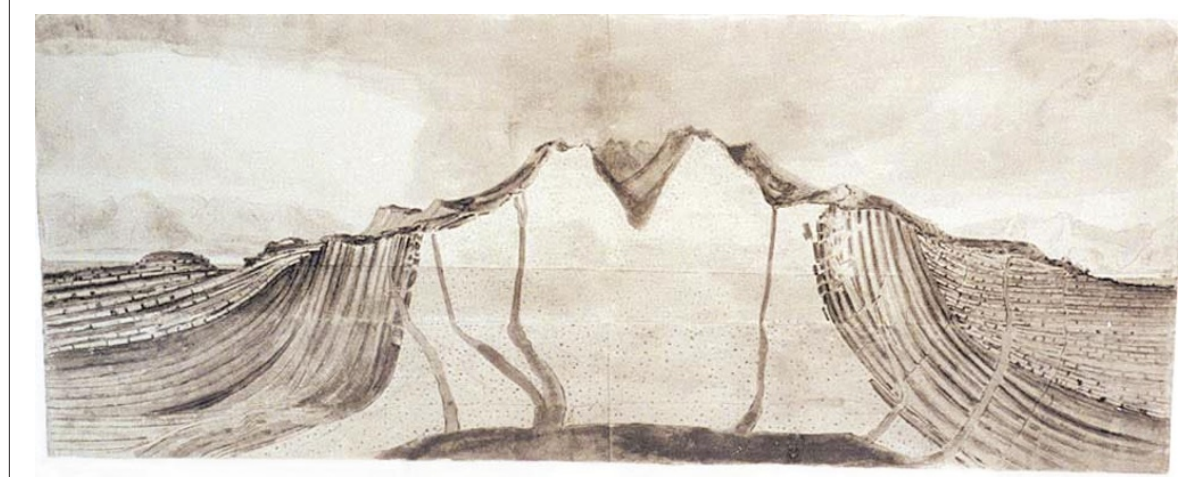

Hutton's geological observations, such as this watercolour, paved the way for uniformitarianism.
Uniformitarianism

"Until we understand more of past

climates, some of the most modern

Earth science will continue to rely

on one of the oldest geological

assumptions."

Sometimes, the uniformitarian hypothesis is easy to believe. The ice of Greenland is coldest a kilometre down because it has not finished warming from the last ice age. Simple assumptions, such as that past ice and present ice have similar thermal properties, and that space aliens have not been installing chilling units, then allow us to constrain Greenland ice-age temperatures.

But in other cases the uniformitarian hypothesis is harder to justify. Today, the average precipitation in colder places is isotopically lighter, with a highly reproducible slope. This relation has often been used to estimate past temperatures at a place. But when this substitution of space for time was tested against the temperature of Greenland's ice sheet, the isotope thermometer erred by a factor of more than two. Similarly, early work applying recent spatial patterns of ocean-sediment shell types to past temperatures missed most of the significant ice-age cooling of the tropical Pacific, affecting our ability to understand the glacial world.

The people applying the uniformitarian hypothesis to climate change know this well, and are rapidly developing new indicators. Agreement of independent indicators is harder to dismiss, as when two new palaeothermometers based on trapped gases in Greenland ice agreed beautifully with the temperatures in the ice sheet. New indicators often rely on physically simple systems, avoiding the confounding effects of other influences. Until we understand more of past climates, some of the most modern Earthscience research will continue to rely heavily on one of the oldest Earth-science assumptions, that of uniformitarianism.

Richard B. Alley is in the Environment Institute and Department of Geosciences, Pennsylvania State University, 204A Deike Building, University Park, Pennsylvania 16802, USA.

\section{FURTHER READING}

Alley, R. B. The Two-Mile Time Machine: Ice Cores, Abrupt Climate Change, and Our Future (Princeton Univ. Press, 2000).

\section{WEBLINKS}

PAGES, the Past Global Changes project

http://wwww.pages. unibe.ch

National Geophysical Data Center

http://www.ngdc.noaa.gov/paleo/paleo.html 